\title{
Charging of mesospheric aerosol particles: the role of photodetachment and photoionization from meteoric smoke and ice particles
}

\author{
M. Rapp \\ Leibniz-Institute of Atmospheric Physics at the University of Rostock, Kühlungsborn, Germany \\ Received: 29 April 2009 - Revised: 3 June 2009 - Accepted: 5 June 2009 - Published: 11 June 2009
}

\begin{abstract}
Time constants for photodetachment, photoemission, and electron capture are considered for two classes of mesospheric aerosol particles, i.e., meteor smoke particles (MSPs) and pure water ice particles. Assuming that MSPs consist of metal oxides like $\mathrm{Fe}_{2} \mathrm{O}_{3}$ or $\mathrm{SiO}$, we find that during daytime conditions photodetachment by solar photons is up to 4 orders of magnitude faster than electron attachment such that MSPs cannot be negatively charged in the presence of sunlight. Rather, even photoemission can compete with electron capture unless the electron density becomes very large $\left(\gg 1000 \mathrm{~cm}^{-3}\right)$ such that MSPs should either be positively charged or neutral in the case of large electron densities. For pure water ice particles, however, both photodetachment and photoemission are negligible due to the wavelength characteristics of its absorption cross section and because the flux of solar photons has already dropped significantly at such short wavelengths. This means that water ice particles should normally be negatively charged. Hence, our results can readily explain the repeated observation of the coexistence of positive and negative aerosol particles in the polar summer mesopause, i.e., small MSPs should be positively charged and ice particles should be negatively charged. These results have further important implications for our understanding of the nucleation of mesospheric ice particles as well as for the interpretation of incoherent scatter radar observations of MSPs.
\end{abstract}

Keywords. Atmospheric composition and structure (Aerosols and particles; Middle atmosphere composition and chemistry) - Ionosphere (Ion chemistry and composition)

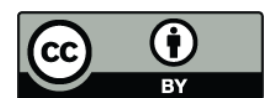

Correspondence to: M. Rapp

(rapp@iap-kborn.de)

\section{Introduction}

In recent years it has been realized that charged aerosol particles play an important role in the physics of the mesosphere. On the one hand, the polar summer mesopause region at altitudes between 80 and $90 \mathrm{~km}$ is host to ice particles which may form under the prevailing extreme thermal conditions with mean minimum temperatures of about $130 \mathrm{~K}$ (e.g., Lübken, 1999). These particles have been known for many years and are nowadays routinely observed by many different techniques as noctilucent clouds, NLC, when observed from the ground, or as polar mesospheric clouds, PMC, when observed from space (e.g., Witt, 1969; DeLand et al., 2006). In addition, it is now understood that these particles acquire a charge in the ambient D-region and modify the properties of the plasma which ultimately leads to the generation of extremely strong radar echoes which are now known as polar mesosphere summer echoes or PMSE (e.g., Rapp and Lübken, 2004).

On the other hand, there is a second class of particles, so-called meteor smoke particles (MSPs), whose existence had long been suggested on theoretical grounds (Rosinski and Snow, 1961; Hunten et al., 1980), but whose experimental detection has bothered the community until only recently (see Rapp et al., 2007, for a recent review). MSPs are thought to be the result of meteoroid ablation and subsequent re-condensation and should hence exist in the entire mesosphere and throughout the year. Consequently, it has been suggested that these particles are involved in a number of atmospheric processes such as the nucleation of mesospheric ice particles (e.g., Rapp and Thomas, 2006), metal atom chemistry (e.g., Plane, 2003), and even the nucleation of polar stratospheric clouds being responsible for ozone destruction during polar spring (Voigt et al., 2005). Just like the mesospheric ice particles, MSPs are embedded in the plasma of the D-region such that they should also become charged, and in fact most observations of MSPs available today have

Published by Copernicus Publications on behalf of the European Geosciences Union. 
taken advantage of this fact and detected the particles using electrostatic in situ detectors and recently also using incoherent scatter radar techniques (see Rapp et al., 2007, for a recent review).

The charging of mesospheric particles has traditionally been described as being due to a balance of capture processes of thermal electrons and ions such that common sense in the community has long been that the particles should be negatively charged owing to the much smaller electron mass and hence much larger electron mobility (Reid, 1990; Jensen and Thomas, 1991; Rapp and Lübken, 2001). Photoemission as an additional charging mechanism was also suggested for mesospheric ice particles (Havnes et al., 1990) but quantitative calculations on the basis of laboratory measurements showed that the work function of pure ice is too large to allow photoemission to compete with electron capture and result in a positive particle charge. This applies unless the particles become contaminated for example by atomic sodium as the consequence of a fresh input of metals by a rather large meteoroid (e.g., Vondrak et al., 2006). However, these authors also showed that this is a rather rare scenario which should happen in about $2 \%$ of the time only.

Despite these findings, compelling evidence has accumulated over the years for the co-existence of negatively and positively charged particles under the conditions of the polar summer mesopause. While the initial observation of apparently positively charged ice particles in a noctilucent cloud by Havnes et al. (1996) has recently been challenged by the same group as being due to secondary charging effects (Havnes and Næsheim, 2007), there now are a number of independent observations that appear to show consistently that during polar summer there is indeed a population of small positively charged aerosol particles which cannot be explained by instrumental effects but which appears to be real. These are the Gerdien condenser observations of Croskey et al. (2001) and Mitchell and Croskey (2001) which show positive ions of low mobility throughout the altitude range from 70 to $90 \mathrm{~km}$ from two sounding rocket flights in 1991 and 1999. On the basis of laboratory measurements of ion mobilities, Mitchell and Croskey (2001) estimate that measured mobilities correspond to positive ion masses of $10000 \mathrm{amu}$ or greater corresponding to particle sizes in the low nanometer size range depending on particle density. Interestingly, simultaneous measurements with an electrostatic blunt probe revealed the presence of negatively charged particles in an altitude range where PMSE were observed thus hinting at the coexistence of both charges at those altitudes. Additional evidence for the coexistence of small positively charged particles and large negatively charged particles has since been presented by several authors using independent techniques such as simple magnetically shielded probes (Smiley et al., 2006), a sophisticated aerosol particle spectrometer (Robertson et al., 2009), and on the basis of measured net particle charges and electron and ion densities in combination with modeling (Brattli et al., 2009). How- ever, up to date, no compelling physical explanation has been presented for these observations.

In this short note, we will reconsider the question of mesospheric particle charging by explicitly taking into account the effect of photodetachment of electrons from charged particles which has been completely ignored in previous work. In addition, we will consider different particle materials, i.e., water ice and metal oxides like hematite $\left(\mathrm{Fe}_{2} \mathrm{O}_{3}\right)$ and silicon oxide $(\mathrm{SiO})$ mimicking meteoric smoke particles. Since the composition of meteor smoke has so far not been directly determined from observations, we base this choice on statements by Plane (2003) who argued that meteoric smoke particles are presumably composed of metallic compounds which polymerize together with silicon oxides. In a later study, Saunders and Plane (2006) studied corresponding systems in the laboratory and - among a few other metal oxides - explicitly suggested hematite to be a strong candidate for meteor smoke particles. In addition, Bohren and Olivero (1984) actually reported the direct observation of hematite-particles from mesospheric altitudes. Taking these arguments together with constraints regarding the availability of complex refractive index-data down to $\sim 120 \mathrm{~nm}$ (i.e., in order to capture photodetachment and photoionization due to Ly- $\alpha$ radiation), hematite and $\mathrm{SiO}$ were chosen for the current purpose. Corresponding calculations are presented in Sect. 2 followed by a short discussion and our conclusions in Sect. 3 in which we close with recommendations for future experiments.

\section{Time constant analysis}

Photodetachment and photoionization time constants have been calculated according to

$\tau_{p}=\left(\int_{0}^{\lambda^{*}} F(\lambda) \cdot \sigma(r, n, \lambda) \cdot Y(\lambda) \cdot d \lambda\right)^{-1}$

where $F(\lambda)$ is the flux of solar photons at wavelength $\lambda$, $\sigma(r, n, \lambda)$ is the absorption cross section of the particle depending on particle radius, complex refractive index $n=$ $m+i k$, and wavelength, and $Y$ is the quantum yield. $\lambda^{*}=$ $h c / E^{*}$ is the critical wavelength up to which the integration is carried out where $h$ is Planck's constant, $c$ is the speed of light, and $E^{*}$ is the threshold energy for photodetachment (= the electron affinity) or photoionization (= the work function), respectively. Note that Eq. (1) describes photodetachment/photoemission as a single photon process, i.e., it is assumed that the photon is first absorbed by the particle, and if the photon energy is larger than the electron affinity/work function, then an electron is detached/emitted with the probability $Y$.

Values of $\tau_{p}$ will be compared to time constants for electron attachment which we calculated according to

$\tau_{e}=\frac{1}{\alpha_{e} \cdot N_{e}}$ 
where

$\alpha_{e}=\pi r^{2} \cdot v_{t} \cdot\left(1+\sqrt{\frac{e^{2}}{8 \epsilon_{0} \cdot k \cdot T \cdot r}}\right)$

is the electron capture rate calculated based on the theory developed by Natanson (1960), where $r$ is the particle radius, $v_{t}$ is the mean thermal velocity of the electrons, $e$ is the electron charge, $\epsilon_{0}$ is the permittivity of space, $k$ is Boltzmann's constant, and $T$ is temperature which is taken equal for all charged and neutral constituents. Finally, $N_{e}$ is the free electron density. We note that Eq. (3) is known to become invalid at particle radii less than about $1 \mathrm{~nm}$ (Megner and Gumbel, 2009; Vostrikov and Dubov, 2006a,b) below which quantum mechanical effects such as the detailed electronic structure of the particle (or better cluster) need to be taken into account. In the same vein, we also note that application of Eq. (1) to very small particles is most probably as problematic as application of Natanson (1960)'s theory for electron capture rates. Equation (1) assumes that the absorption properties of the particles can be described on the basis of a refractive index which has been measured for bulk material and not for nanoparticles. Hence, one must expect that the corresponding formulation becomes erroneous at some lower critical radius. While quantitative information from laboratory measurements of the photoemission properties of MSP-type nanoparticles is - to the best of our knowledge - not available, the best we can do is restrict all following calculations to radii larger than a reasonable assumed lower limit which we here chose as $1 \mathrm{~nm}$.

While the necessary laboratory evidence regarding the actual value of such a lower radius limit is not available, we offer the following plausibility argument in favor of our choice. Using the model results of Megner et al. (2008) (their Figs. 4 and 5), we see that they arrive at total MSP number densities of about $70000 \mathrm{~cm}^{-3}$ and $\leq 1000 \mathrm{~cm}^{-3}$ for radii larger than $1 \mathrm{~nm}$ at altitudes above $80 \mathrm{~km}$. Quite evidently, if all particles would be negatively/positively charged during night/day that would make an enormous effect on the ambient ionization. I.e., during the day the extra source of free electrons from photoemission would increase the electron density by orders of magnitude as compared to what is observed and the opposite would happen during nighttime. However, applying the same argument for the case of particles larger than about $1 \mathrm{~nm}$, we see that the order of magnitude is at least reasonable. Evidently, however, laboratory measurements of processes like electron capture and photoemission in the transition size region from molecular clusters to nanoparticles are badly needed in order to justify or falsify the assumptions made here.

For the case of photodetachment and photoionization, we note that the dependence of the absorption cross section on the complex refractive index $n$ and the threshold wavelength $\lambda^{*}$ makes this a highly material-specific problem. This is illustrated in Fig. 1 where we show absorption cross sections for water ice, $\mathrm{Fe}_{2} \mathrm{O}_{3}$, and $\mathrm{SiO}$ which were calculated using Mie-theory (Bohren and Huffman, 1983) as well as the solar spectrum at the top of the atmosphere as taken from Brasseur and Simon (1981) for wavelengths below $725 \mathrm{~nm}$ and from the ASTM G173-03 reference spectra (http://rredc.nrel. gov/solar/spectra/am1.5/ASTMG173/ASTMG173.html) for longer wavelengths. Refractive indices necessary for these calculations were taken from the compilation by Warren (1984) for water ice, and from the internet data bases http: //www.astro.uni-jena.de/Laboratory/OCDB/ oxsul.html and http://luxpop.com/RefractiveIndexList.html for the cases of $\mathrm{Fe}_{2} \mathrm{O}_{3}$ and $\mathrm{SiO}$, respectively. This figure demonstrates the enormous difference in absorption between water ice and the metal oxides. While water ice basically does not absorb at all (i.e., is transparent) at wavelengths between $\sim 180 \mathrm{~nm}$ and the infrared, the iron and silicon oxides show strong absorption from the UV throughout the visible wavelength range. Since the effect of photodetachment/photoemission is determined by the product of the solar flux times the absorption cross section at wavelengths (energies) less (larger) than the wavelengths corresponding to the electron affinity/workfunction of the particular material, these products for different particle materials are shown in the right panel of Fig. 1. There, we have also marked the work functions of water ice $(8.7 \mathrm{eV})$ and $\mathrm{Fe}_{2} \mathrm{O}_{3}(5.5 \mathrm{eV})$ and the electron affinity of $\mathrm{Fe}_{2} \mathrm{O}_{3}(2.0 \mathrm{eV}$; the electron affinity of water ice is $0.8 \mathrm{eV}$ ) (Baron et al., 1978; Wang et al., 1996; do Couto et al., 2006). This demonstrates that photodetachment from water ice is governed by Ly- $\alpha$-photons and wavelengths from $\sim 1000 \mathrm{~nm}$ to $1467.2 \mathrm{~nm}$ (corresponding to $0.8 \mathrm{eV}$ ). Owing to its large work function of $8.7 \mathrm{eV}$, photoemission from water ice is almost exclusively due to Ly- $\alpha$. For the metal oxides, however, also visible wavelengths significantly contribute to these processes.

Consequently, it is no surprise that photodetachment time constants for these oxides are about 6 orders of magnitude smaller than those for water ice. This is clearly seen in Fig. 2 where corresponding time constants are shown as a function of particle radius. We note that these rates have been calculated assuming an upper estimate of the photoelectron yield of 1 for $\mathrm{Fe}_{2} \mathrm{O}_{3}$ following the arguments in Rapp and Strelnikova (2009) and according to Baron et al. (1978) for water ice $(\sim 0.01)$. However, we will see later that the precise choice of $Y$ does not affect our main conclusions anyway. At this point, we further note that the issue of charging is not affected by sedimentation of particles owing to their gravity. Sedimentation time scales are at least three orders of magnitudes larger than charging time scales and can hence be ignored in the present context.

Turning first to the left panel of Fig. 2 showing the results for $\mathrm{Fe}_{2} \mathrm{O}_{3}$ (results for $\mathrm{SiO}$ are very similar) we see that photodetachment is more than 4 orders of magnitude faster than electron attachment to a neutral particle. Hence, there is clearly no means by which a MSP consisting of $\mathrm{Fe}_{2} \mathrm{O}_{3}$ or a material with similar absorption properties could become 

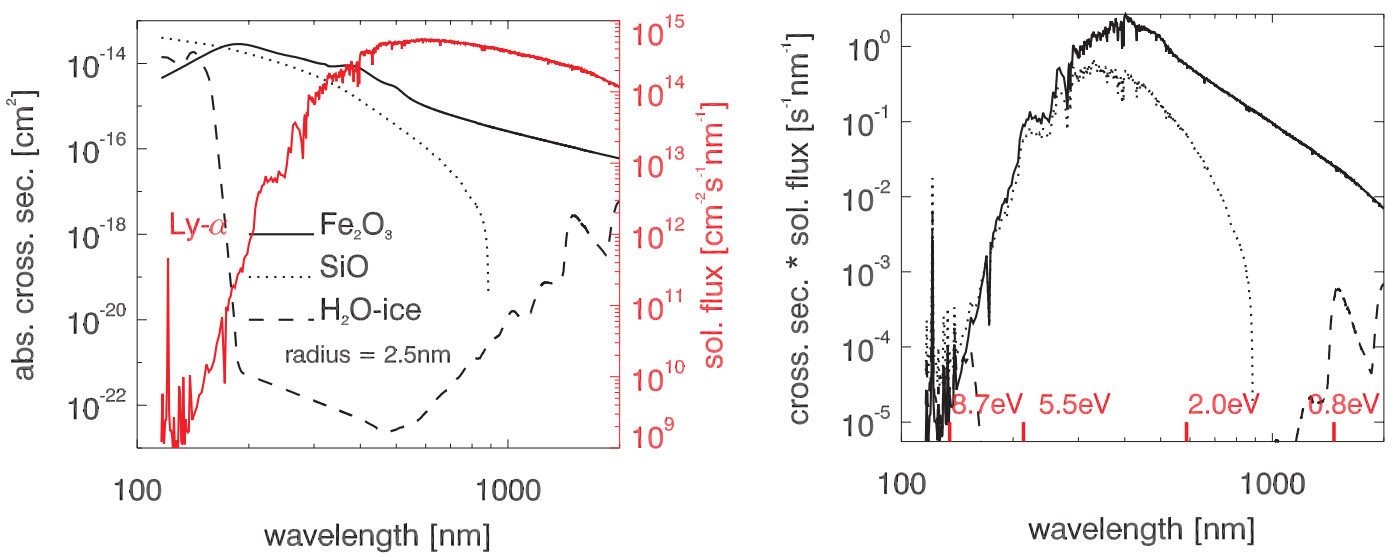

Fig. 1. Left panel: Wavelength-dependence of the absorption cross sections for spherical particles composed of hematite $\left(\mathrm{Fe}_{2} \mathrm{O}_{3}\right.$, solid line), silicon oxide ( $\mathrm{SiO}$, dotted line), and water ice (dashed line), for a particle radius of $2.5 \mathrm{~nm}$ (left ordinate), and the solar spectrum at mesospheric heights (right red ordinate). Right panel: Corresponding products of absorption cross sections and the solar flux. Note that values for all materials fall close on each other at wavelengths around Ly- $\alpha$. In addition, threshold-energies for the photoionization of water ice $(8.7 \mathrm{eV})$ and $\mathrm{Fe}_{2} \mathrm{O}_{3}(5.5 \mathrm{eV})$, as well as the electron affinity of water ice $(0.8 \mathrm{eV})$ and $\mathrm{Fe}_{2} \mathrm{O}_{3}(2 \mathrm{eV})$ have been indicated by vertical red lines on the abscissa.
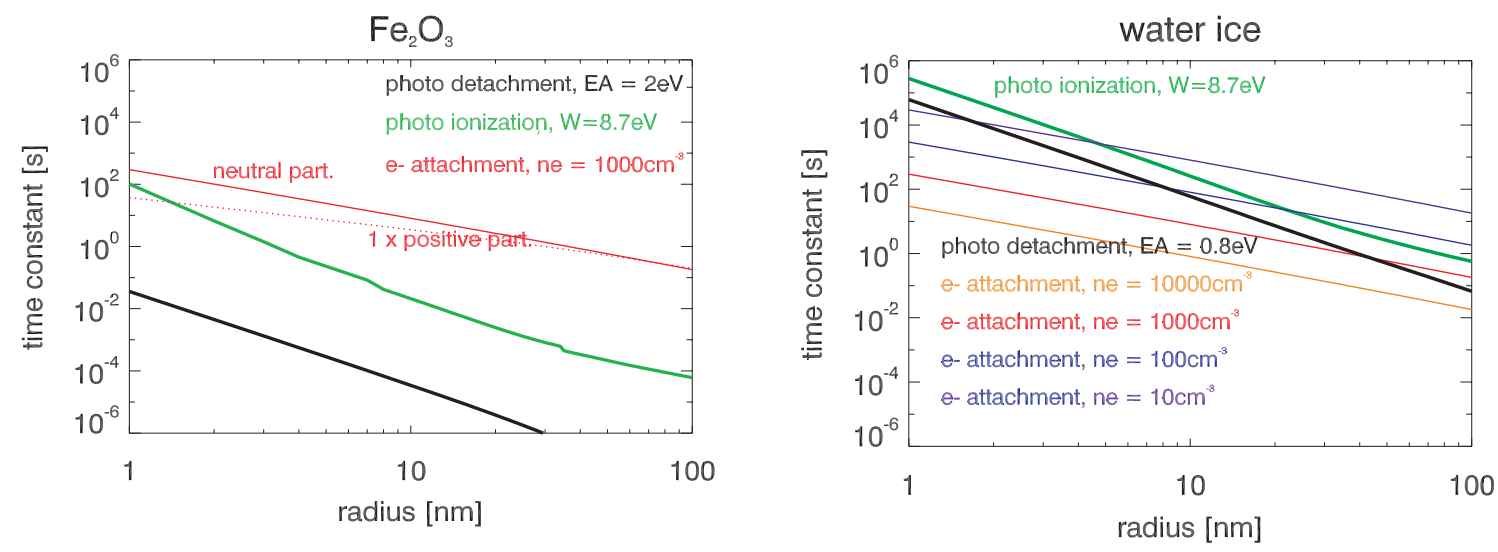

Fig. 2. Left panel: Time constants for photodetachment (in black), photoemission (in green), and electron attachment (red lines) of $\mathrm{Fe}_{2} \mathrm{O}_{3}$ particles as a function of particle radius. Right panel: Time constants for photodetachment (black line), photoemission (in green), as well as electron attachment for electron densities from $10 \mathrm{~cm}^{-3}-10000 \mathrm{~cm}^{-3}$ (orange, red, and blue lines) as a function of particle radius.

negatively charged under conditions of solar illumination. We next turn to the process of photoemission. Interestingly, time constants for photoemission are smaller than $100 \mathrm{~s}$ for all radii, corresponding to photoemission rates larger than $10^{-2} / \mathrm{s}$. Such large rates were postulated by Brattli et al. (2009) in order to explain their observations which require an undetected population of small positively charged particles to reach charge neutrality. In addition, if we compare photoemission rates to rates of electron attachment for neutral and singly positively charged particles, we see that photoemission is faster for all radii except for those less than $\sim 1.5 \mathrm{~nm}$ for which electron attachment to a singly positively charged particle might be faster than photoemission for an assumed electron density of $1000 \mathrm{~cm}^{-3}$. In this case, the MSP-fraction smaller than this radius could actually become neutralized. Note, however, that the photodetachment process is so much faster than electron attachment in any case, that there is indeed no means by which the particles could become negative. Importantly, this is even true if the rather large yield assumed for MSPs was significantly smaller.

Comparing this situation to the same calculations for water ice, we see that here the situation is just opposite. Here, photodetachment and hence, of course, also photoionization is such a slow and ineffective process that even for small electron densities, particles become negatively charged. Interestingly, however, we also see that as the electron density goes 
to zero, i.e., as a larger and larger fraction of the electrons is bound on the particles, photodetachment actually becomes a limiting factor for the further reduction of electron density. Hence, this process should actually be considered when trying to model electron biteout situations in comparison to observations.

\section{Conclusions}

We have shown above that photodetachment of electrons from charged MSPs is a dominant process which must be taken into account for calculations of the charge state of MSPs. Quite clearly, if MSPs do consist of $\mathrm{Fe}_{2} \mathrm{O}_{3}, \mathrm{SiO}$ or a material with comparable absorption properties, MSPs cannot be charged negatively under conditions of sunlight such as in the polar summer mesopause region. Rather, unless the electron density becomes very large, our calculations show that MSPs should be positively charged during daytime. These calculations can hence readily explain observations of the coexistence of positively and negatively charged particles in mesospheric ice clouds: while the small MSPs can only be positively charged with a potential fraction of neutral particles depending on the electron density, photodetachment and photoemission are negligible for mesospheric ice particles. Hence, these must be negatively charged except for the rare event of a fresh significant input of meteoric metals of low work function (Vondrak et al., 2006).

We note that this conclusion (i.e., MSP are likely positively charged during daytime) has further important implications for the nucleation of mesospheric ice particles (Gumbel and Megner, 2009; Megner and Gumbel, 2009) as well as for the interpretation of MSP-observations using incoherent scatter radar (Strelnikova et al., 2007).

In order to test the here presented ideas, rocket borne instruments such as the size and charge-resolving aerosol mass spectrometer recently developed by Robertson et al. (2009) should be launched outside the polar summer under daytime and nighttime conditions, respectively. If the here described ideas are correct, MSPs during daytime and preferably moderate electron densities should be positively charged whereas those measured during nighttime (and not too low electron densities, see Rapp et al. (2005) for a discussion of corresponding complications owing to the role of negative ions) should be negatively charged. Finally, the applicability of our ideas to particles at the smallest sizes should be tested with suitable laboratory investigations of processes like electron capture and photoemission in the transition size region from molecular clusters to nanoparticles.

Acknowledgements. The author acknowledges support of this research by the German Space Center in the frame of the ECOMAprojects under DLR-grants 50OE0301 and 50OE0801. Fruitful discussions with J. Gumbel and helpful comments by a referee are gratefully acknowledged.
Topical Editor C. Jacobi thanks one anonymous referee for her/his help in evaluating this paper.

\section{References}

Baron, B., Hoover, D., and Williams, F.: Vacuum ultraviolet photoelectric emission from amorphous ice, J. Comp. Phys., 68, 19971999, 1978.

Bohren, C. F. and Huffman, D. R.: Absorption and scattering of light by small particles, Wiley, New York, 1983.

Bohren, C. F. and Olivero, J. J.: Evidence for haematite particles at $60 \mathrm{~km}$ altitude, Nature, 310, 216-218, 1984.

Brasseur, G. and Simon, P.: Stratospheric chemical and thermal response to long term variability in solar UV-radiance, J. Geophys. Res., 86, 7343-7362, 1981.

Brattli, A., Lie-Svendsen, Ø., Svenes, K., Hoppe, U.-P., Strelnikova, I., Rapp, M., Latteck, R., and Friedrich, M.: The ECOMA 2007 campaign: rocket observations and numerical modelling of aerosol particle charging and plasma depletion in a PMSE/NLC layer, Ann. Geophys., 27, 781-796, 2009, http://www.ann-geophys.net/27/781/2009/.

Croskey, C., Mitchell, J., Friedrich, M., Torkar, K., Hoppe, U.-P., and Goldberg, R.: Electrical structure of PMSE and NLC regions during the DROPPS program, Geophys. Res. Lett., 28, 14271430, 2001.

DeLand, M. T., Shettle, E. P., Thomas, G. E., and Olivero, J. J.: Spectral measurements of PMCs from SBUV/2 instruments, J. Atmos. Sol. Terr. Phys., 68, 65-77, 2006.

do Couto, P. C., Cabral, B. J. C., and Canuto, S.: Electron binding energies of water clusters: Implications for the electronic properties of liquid water, 429, 129-135, doi:doi:10.1016/j.cplett.2006. 08.046, 2006.

Gumbel, J. and Megner, L.: Charged meteoric smoke as ice nuclei in the mesosphere: Part 1 - A review of basic concepts, J. Atmos. Solar-Terr. Phys., in press, doi:10.1016/j.jastp.2009.04.012, 2009.

Havnes, O. and Næsheim, L. I.: On the secondary charging effects and structure of mesospheric dust particles impacting on rocket probes, Ann. Geophys., 25, 623-637, 2007, http://www.ann-geophys.net/25/623/2007/.

Havnes, O., de Angelis, U., Bingham, R., Goertz, C. K., Morfill, G. E., and Tsytovich, V.: On the role of dust in the summer mesopause, J. Atmos. Terr. Phys., 52, 637-643, 1990.

Havnes, O., Trøim, J., Blix, T., Mortensen, W., Næsheim, L. I., Thrane, E., and Tønnesen, T.: First detection of charged dust particles in the Earth's mesosphere, J. Geophys. Res., 101, 1083910847, 1996.

Hunten, D. M., Turco, R. P., and Toon, O. B.: Smoke and Dust Particles of Meteoric Origin in the Mesosphere and Stratosphere, J. Atmos. Sci., 37, 1342-1357, 1980.

Jensen, E. and Thomas, G. E.: Charging of mesospheric particles: implications of electron density and particle coagulation, J. Geophys. Res., 96, 18603-18615, 1991.

Lübken, F.-J.: Thermal structure of the Arctic summer mesosphere, J. Geophys. Res., 104, 9135-9149, 1999.

Megner, L. and Gumbel, J.: Charged meteoric smoke as ice nuclei in the mesosphere: Part 2 - A feasibility study, J. Atmos. SolarTerr. Phys., in press, doi:10.1016/j.jastp.2009.05.002, 2009. 
Megner, L., Siskind, D. E., Rapp, M., and Gumbel, J.: Global and temporal distribution of meteoric smoke: A two-dimensional simulation study, J. Geophys. Res., 113, D03202, doi:10.1029/ 2007JD009054, 2008.

Mitchell, J. D. and Croskey, C. L.: Electrical structure of noctilucent cloud and polar mesosphere summer echo regions, Adv. Space Res., 28, 1027-1036, 2001.

Natanson, G. L.: On the theory of the charging of amicroscopic aerosol particles as a result of capture of gas ions, Sov. Phys. Tech. Phys., 5, 538-551, 1960 (English Translation).

Plane, J. M. C.: Atmospheric chemistry of meteoric metals, Chem. Rev., 103, 4963-4984, 2003.

Rapp, M. and Lübken, F.-J.: Modelling of particle charging in the polar summer mesosphere: Part 1 - general results, J. Atmos. Sol. Terr. Phys., 63, 759-770, 2001.

Rapp, M. and Lübken, F.-J.: Polar mesosphere summer echoes (PMSE): Review of observations and current understanding, Atmos. Chem. Phys., 4, 2601-2633, 2004, http://www.atmos-chem-phys.net/4/2601/2004/.

Rapp, M. and Strelnikova, I.: Measurements of meteor smoke particles during the ECOMA-2006 campaign: 1. particle detection by active photoionization, J. Atmos. Sol. Terr. Phys., 71, 477-485, 2009.

Rapp, M. and Thomas, G. E.: Modeling the microphysics of mesospheric ice particles: Assessment of current capabilities and basic sensitivities, J. Atmos. Sol. Terr. Phys., 68, 715-744, 2006.

Rapp, M., Hedin, J., Strelnikova, I., Friedrich, M., Gumbel, J., and Lübken, F.-J.: Observations of positively charged nanoparticles in the nighttime polar mesosphere, Geophys. Res. Lett., 32, L23821, doi:10.1029/2005GL024676, 2005.

Rapp, M., Strelnikova, I., and Gumbel, J.: Meteoric smoke particles: evidence from rocket and radar techniques, Adv. Space Res., 40, doi:10.1016/j.asr.2006.11.021, 809-817, 2007.

Reid, G. C.: Ice particles and electron "bite-outs" at the summer polar mesopause, J. Geophys. Res., 95, 13,891-13,896, 1990.

Robertson, S., Horányi, M., Knappmiller, S., Sternovsky, Z., Holzworth, R., Shimogawa, M., Friedrich, M., Torkar, K., Gumbel, J., Megner, L., Baumgarten, G., Latteck, R., Rapp, M., Hoppe, U.-P., and Hervig, M. E.: Mass analysis of charged aerosol particles in NLC and PMSE during the ECOMA/MASS campaign, Ann. Geophys., 27, 1213-1232, 2009, http://www.ann-geophys.net/27/1213/2009/.
Rosinski, J. and Snow, R. H.: Secondary particulate matter from meteor vapors, J. Met., 18, 736-745, 1961.

Saunders, R. W. and Plane, J. M. C.: A laboratory study of meteor smoke analogues: Composition, optical properties and growth kinetics, J. Atmos. Sol. Terr. Phys., 68, 2182-2202, 2006.

Smiley, B., Rapp, M., Blix, T. A., Robertson, S., Horanyi, M., Latteck, R., and Fiedler, J.: Charge and size distribution of mesospheric aerosol particles measured inside NLC and PMSE during MIDAS MaCWAVE 2002, J. Atmos. Sol. Terr. Phys., 68, 114123, 2006.

Strelnikova, I., Rapp, M., Raizada, S., and Sulzer, M.: Meteor smoke particle properties derived from Arecibo incoherent scatter radar observations, Geophys. Res. Lett., 34, L15815, doi:10.1029/2007GL030635, 2007.

Voigt, C., Schlager, H., Luo, B. P., Dörnbrack, A., Roiger, A., Stock, P., Curtius, J., Vössing, H., Borrmann, S., Davies, S., Konopka, P., Schiller, C., Shur, G., and Peter, T.: Nitric Acid Trihydrate (NAT) formation at low NAT supersaturation in Polar Stratospheric Clouds (PSCs), Atmos. Chem. Phys., 5, 13711380, 2005, http://www.atmos-chem-phys.net/5/1371/2005/.

Vondrak, T., Plane, J. M. C., and Meech, S. R.: Photoemission from sodium on ice: a mechanism for positive and negative charge coexistence in the mesosphere, Phys. Chem. B Lett., 110, 38603863, 2006.

Vostrikov, A. A. and Dubov, D. Y.: Absolute cross sections of electron attachment to molecular clusters: Part I. Formation of $\left(\mathrm{CO}_{2}\right)_{N}^{-}$, Technical Physics, 51, 540-547, 2006a.

Vostrikov, A. A. and Dubov, D. Y.: Absolute cross sections of electron attachment to molecular clusters: Part II. Formation of $\left(\mathrm{H}_{2} \mathrm{O}\right)_{N}^{-},\left(\mathrm{N}_{2} \mathrm{O}\right)_{N}^{-},\left(\mathrm{N}_{2}\right)_{N}^{-}$, Technical Physics, 51, 1537-1552, 2006b.

Wang, L. S., Wu, H., and Desai, S. R.: Sequential oxygen atom chemisorption on surfaces of small iron clusters, Phys. Rev. Lett., 76, 4853-4856, 1996.

Warren, S. G.: Optical constants of ice from the ultraviolet to the microwave, Appl. Optics, 23, 1206-1225, 1984.

Witt, G.: The nature of noctilucent clouds, Space Res., IX, 157$169,1969$. 